\title{
Paralisia de Bell subsequente a ritidoplastia
}

\section{Bell's palsy subsequent to rhytidectomy}

Cristiano D. Silveira

RAMOS $^{1}$

MARCELO WILSON ROCHA

AlmeIDA $^{2}$

Leonardo Fernandes de

Souza Aguiar ${ }^{2}$

Marcelo Chemin Cury ${ }^{3}$

Trabalho realizado na clínica privada do autor, Juiz de Fora, MG, Brasil.

Artigo submetido no SGP (Sistema de Gestão de Publicações) da RBCP.

Artigo recebido: 22/9/2009 Artigo aceito: 19/2/2010

\begin{abstract}
RESUMO
Introdução: A paralisia facial periférica é uma entidade que pode deixar sequelas estéticas e funcionais importantes nos pacientes. De acordo com a literatura, a paralisia de Bell (PB) é a causa mais comum, representando de 50 a $80 \%$ dos casos. Porém deve ser considerada como diagnóstico de exclusão. Estima-se uma prevalência ligeiramente maior entre as mulheres e sua incidência é bimodal, com picos na terceira e oitava décadas de vida. A maioria dos pacientes evolui para a recuperação dentro de algumas semanas, embora seja comum uma piora do quadro nas primeiras 48 horas. $\mathrm{O}$ tratamento deve ser realizado no sentido de prevenir complicações e as condutas medicamentosas não estão consagradas. Como fatores de risco para a PB têm sido relatados hipertensão arterial, diabete mellitus, gravidez, puerpério e infecção pelo vírus herpes tipo I. Embora existam vários fatores de risco associados à $\mathrm{PB}$, em relação à cirurgia de face-lifting existe apenas um caso relatado na literatura. Relato do Caso: No presente estudo, os autores descrevem o segundo caso de paralisia de Bell após a cirurgia de face-lifting.
\end{abstract}

Descritores: Paralisia facial. Paralisia de Bell. Nervo facial. Fatores de risco. Tratamento.

\begin{abstract}
Introduction: The peripheral facial palsy is a disease that can leave significant aesthetical and functional sequelae in patients. According to medical literature, Bell's palsy (BP) is the most common cause, representing from 50 to $80 \%$ of the cases. However, it must be considered as an exclusion diagnosis. A slightly higher prevalence is estimated in women and its incidence is bimodal with peaks in the third and eighth life decades. Most patients recover within weeks, though a worsening degree may be common in the first 48 hours. Treatment must be performed to prevent complications and the medical procedures are not universally accepted. The following have been mentioned as BP risk factors: arterial hypertension, mellitus diabetes, pregnancy, puerperium and infection caused by type I herpes virus. Although there are several BP associated risk factors, regarding face-lifting surgery there is only one reported case in medical literature. Case Report: In the present study, the authors describe the second case of Bell's palsy after face-lifting surgery.
\end{abstract}

Keywords: Facial paralysis. Bells palsy. Facial nerve. Risk factors. Treatment.

1. Membro Titular da Sociedade Brasileira de Cirurgia Plástica; Professor Assistente do Instituto Ivo Pitanguy, Rio de Janeiro, RJ, Brasil.

2. Residente de cirurgia plástica no Instituto Ivo Pitanguy, Rio de Janeiro, RJ, Brasil.

3. Membro especialista da Sociedade Brasileira de Cirurgia Plástica, Cirurgião Plástico, Rio de Janeiro, RJ, Brasil. 


\section{INTRODUÇÃO}

A paralisia facial periférica é uma entidade não rara que pode deixar sequelas estéticas e funcionais importantes nos pacientes. De acordo com a literatura, a paralisia de Bell (PB) é a causa mais comum, representando de 50 a $80 \%$ dos casos $^{1}$. Porém deve ser considerada como diagnóstico de exclusão ${ }^{2}$. Esta forma idiopática foi descrita, em 1821, por Sir Charles Bell ${ }^{3}$.

A PB consiste em um acometimento do VII nervo craniano, de forma aguda, podendo ser precedida por dor na região da mastoide, resultando em paralisia completa ou parcial da mímica facial. Distúrbios da gustação, salivação e lacrimejamento, além de hiperacusia desagradável e hipoestesia na zona de Ramsay-Hunt, podem estar associados ${ }^{4,5}$.

Estima-se que a incidência da PB seja de 20-30 casos por 100 mil habitantes, com prevalência ligeiramente maior entre as mulheres. É rara antes dos 10 anos de idade, e sua incidência é bimodal, com picos na terceira e oitava décadas de vida ${ }^{6-8}$. A maioria dos pacientes evolui para a recuperação dentro de algumas semanas, embora seja comum uma piora do quadro nas primeiras 48 horas $^{6}$. Na paralisia facial periférica idiopática, pode haver recorrência da paralisia em $7 \%$ a $15 \%$ dos casos. Alguns chamam de recidivante, quando ocorre no mesmo lado da face, e alternante, quando ocorre no lado oposto da face, nas paralisias faciais consecutivas recorrentes ${ }^{9}$.

Os fatores de risco relatados para a PB são hipertensão arterial, diabete mellitus, gravidez, puerpério e infecção pelo vírus herpes tipo $\mathrm{I}^{7,10-12}$. Embora existam vários fatores de risco associados à $\mathrm{PB}$, em relação à cirurgia de face-lifting existe apenas um caso relatado na literatura por Castañares, em 1974, que descreveu a $\mathrm{PB}$ coincidentemente ou consequentemente à cirurgia de face-lifting ${ }^{13}$. No presente estudo, os autores descrevem o segundo caso de PB subsequente à ritidoplastia.

\section{RELATO DE CASO}

Paciente do sexo masculino, 59 anos, branco, solteiro, professor, natural de Além Paraíba-MG, com história de ritidoplastia há 12 anos. Ao exame clínico evidenciava cicatrizes pré-pilosas, rarefação pilosa, ptose do terço médio facial, afastamento das bandas platismais e blefarocalaze superior bilateral leve. Notava-se um leve desvio da comissura labial à esquerda, durante a posição estática da face (Figura 1). Foi realizada ritidoplastia secundária em 7/12/2006, com incisão pré-pilosa, respeitando as cicatrizes prévias, com plicatura do SMAS e aproximação das bandas platismais. Não houve abordagem da região frontal. O procedimento foi realizado sob anestesia geral, sem infiltração local, com duração aproximada de 4 horas, sem intercorrências no per e pós-operatório imediato. O paciente recebeu alta no $2^{\circ}$ dia de pós-operatório, ocasião em que foi realizado curativo, retirados os drenos, não apresentando queixas, porém com leve edema generalizado na face de aspecto normal.

No $10^{\circ}$ dia de pós-operatório, apresentava-se sem queixas. Ao exame evidenciava edema localizado reduzido, movimentos da musculatura facial preservados.

Após 3 semanas, o paciente retornou ao consultório com relato que, no dia 25/12/2006, havia despertado pela manhã com a hemiface esquerda paralisada de maneira súbita e que até então a mímica facial estava sem alterações. Buscou auxílio médico, na cidade de origem, onde o encaminharam ao neurologista. Ao exame físico, apresentava paralisia facial troncular esquerda, com alterações frontais, oculares e com desvio da comissura labial para o lado contralateral (Figura 2).

Foram realizadas ressonância nuclear magnética de crânio ( $25^{\circ}$ dia de pós-operatório), que não evidenciou alterações, e eletroneuromiografia de face $\left(44^{\circ}\right.$ dia de pósoperatório), que revelou neuropatia aguda do nervo facial esquerdo com importante comprometimento axonal. O hemograma estava sem alterações. Apresentava-se com a sorologia para Citomegalovírus IgG e IgM negativo e

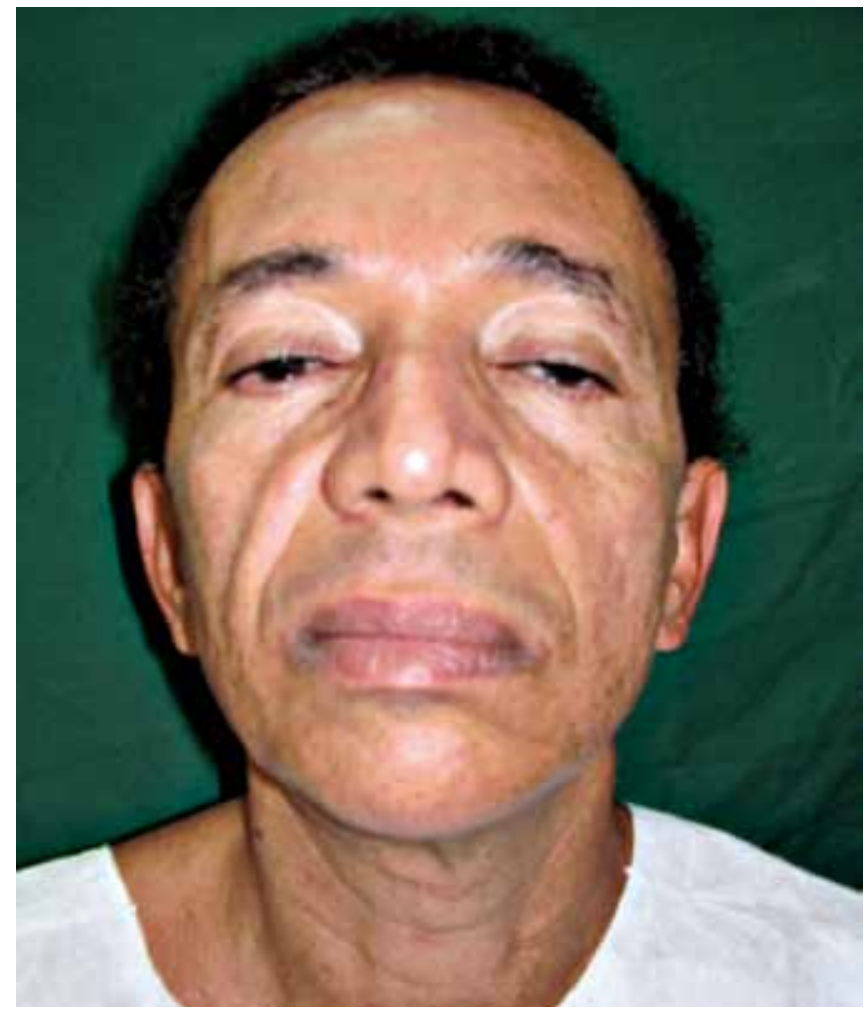

Figura 1 - Pré-operatório - vista anterior. 
sorologia para Herpes Vírus Simples I e II IgG reagente (ELISA) e Herpes Vírus Simples I e II IgM negativo.

Devido à sorologia para Herpes Vírus Simples I e II IgG reagente foi realizada pesquisa para detecção do DNA viral do HSV-1 pela técnica de PCR através da saliva coletada da boca do paciente utilizando-se uma seringa descartável estéril e sem agulha. O exame apresentou-se negativo.

Com base nos exames realizados, confirmou o diagnóstico de $\mathrm{PB}$ subsequente à ritidoplastia. $\mathrm{O}$ paciente foi encaminhado para fisioterapia e tratamento com anti-inflamatórios, vitamina do complexo B e colírio para proteção e lubrificação ocular. Apresentou remissão total da PB após 6 meses de tratamento (Figuras 3 e 4).

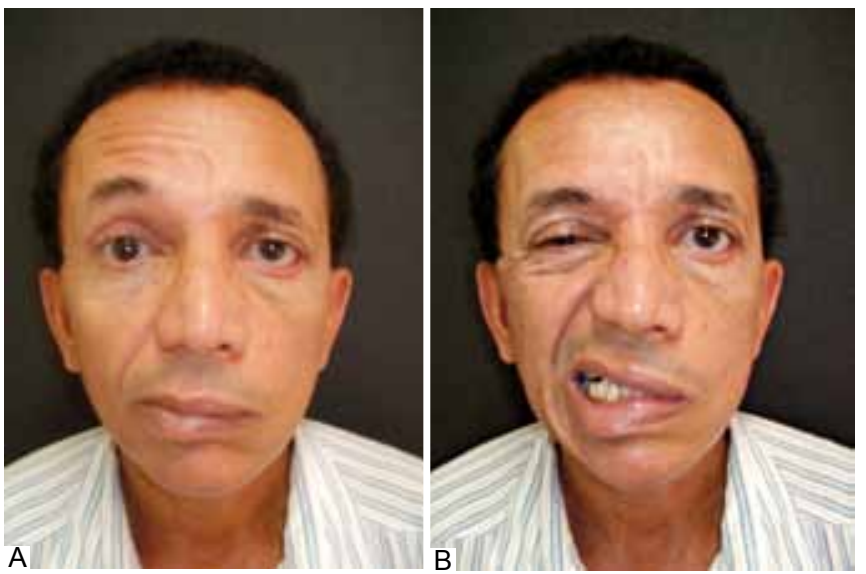

Figura 2 -A: Pós-operatório de 21 dias com mímica evidenciando paralisia de Bell à esquerda. B: Pós-operatório de 21 dias com mímica evidenciando paralisia de Bell à esquerda.
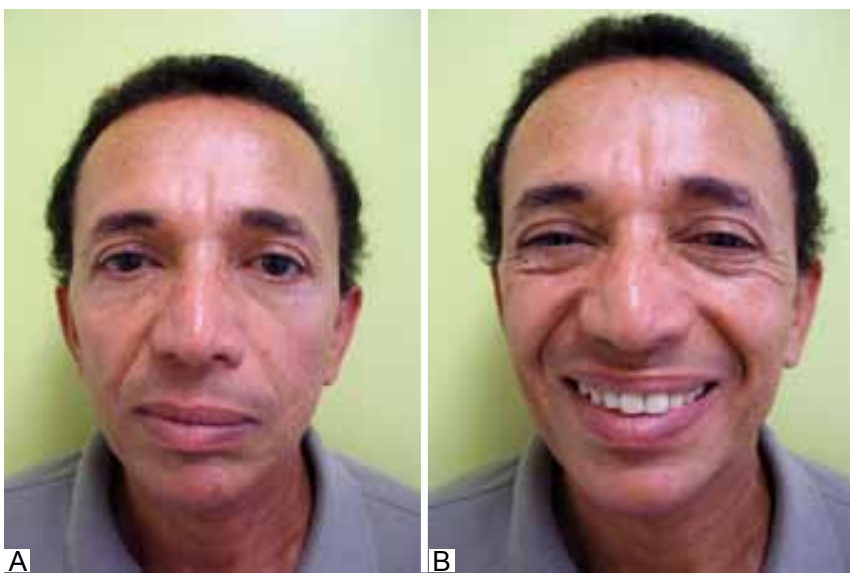

Figura 3 - A: Pós-operatório de 180 dias evidenciando resolução completa do quadro de paralisia de Bell à esquerda. B: Pósoperatório de 180 dias com mímica, evidenciando resolução completa do quadro de paralisia de Bell à esquerda.

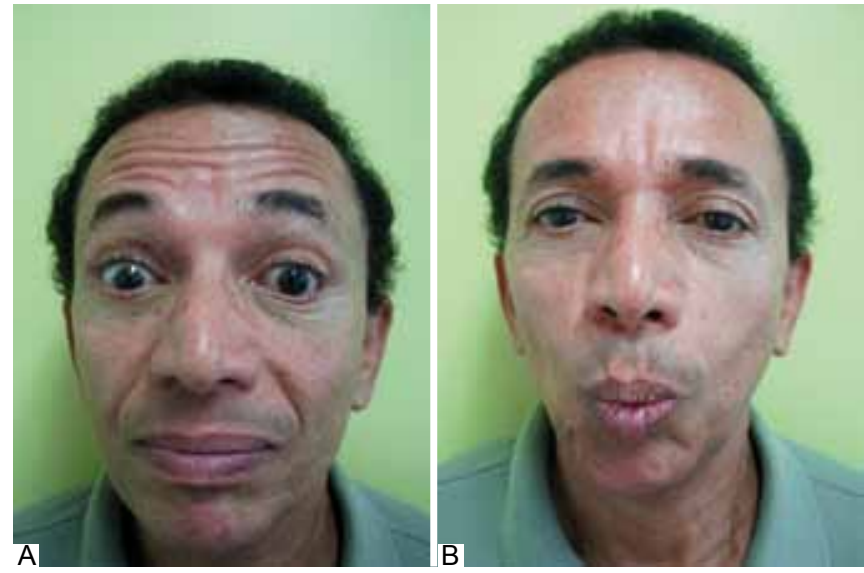

Figura 4-A: Pós-operatório de 180 dias com mímica evidenciando resolução completa do quadro de paralisia de Bell à esquerda. B: Pós-operatório de 180 dias com mímica, evidenciando resolução completa do quadro de paralisia de Bell à esquerda.

\section{DISCUSSÃO}

O comprometimento do nervo facial pode ocorrer devido a várias doenças ${ }^{5,8-10,14-18}$. Entretanto, dentre as causas infecciosas destacam-se os casos com sorologia positiva para o vírus como o herpes simples ${ }^{19}$. A presença do HSV-1 na saliva de pacientes portadores de PB indica que a reativação viral pode ser a etiologia desta doença. A detecção do vírus na saliva destes pacientes não influencia o prognóstico da doença ${ }^{20}$. No presente estudo, o paciente apresentava-se com o teste para detecção do DNA viral do HSV-1 na saliva negativo, excluindo assim uma possível reativação viral.

Quando não há uma etiologia definida, denomina-se a paralisia facial periférica como idiopática ou a frigore. É uma doença relativamente frequente em todo o mundo. Acomete todas as faixas etárias, com prevalência ligeiramente maior entre as mulheres, com recuperação total na maioria dos $\operatorname{casos}^{6-10,14,21}$.

Um estudo avaliando 1521 pacientes portadores de PB indicou que pacientes de faixa etária mais jovem (especialmente abaixo de 20 anos) apresentam prognóstico melhor; a ausência de sintomas prévios ao aparecimento da paralisia está relacionada a pior prognóstico; a ausência de sintomas concomitantes e o hipolacrimejamento durante a paralisia estão relacionados a bom prognóstico, enquanto que a vertigem concomitante à paralisia indica prognóstico desfavorável. Além disso, o início súbito da paralisia está relacionado a bom prognóstico, enquanto que início progressivo indica prognóstico ruim; e o resultado favorável do teste de Hilger está relacionado a bom prognóstico ${ }^{21}$. 
A hipertensão arterial pode estar associada com a PB em $8-36 \%$ dos pacientes ${ }^{13}$. Segundo Brandenburg e Annegers $^{7}$, a hipertensão arterial aumenta o risco de $10-20 \%$, nas mulheres, e 50-60\%, nos homens. Diabete mellitus também aumentaria o risco do acometimento do nervo facial em duas vezes $^{22}$

O diagnóstico da PB é essencialmente clínico, porém é um diagnóstico de exclusão. $\mathrm{O}$ exame físico do paciente deve demonstrar um envolvimento difuso do nervo facial ${ }^{14}$. No caso de apresentação atípica, devemos investigar com exames complementares. O estudo neurofisiológico completo pode estabelecer um prognóstico; após o quinto dia, degeneração axonal está relacionada à recuperação incompleta ${ }^{23}$.

O tratamento da PB deve inicialmente dar importância à proteção ocular, sendo recomendado o uso de solução oftálmica estéril lubrificante e uso de óculos. Estudos randomizados indicam discreto benefício dos esteroides, considerando eventual recuperação completa e sugerem que a administração de corticoide com aciclovir deve ser instituída particularmente nos pacientes com prognóstico ruim ${ }^{10}$.

\section{REFERÊNCIAS}

1. Morgan M, Nathwani D. Facial palsy and infection: the unfolding story. Clin Infect Dis. 1992;14(1):263-71.

2. May M, Klein S. Differential diagnosis of facial nerve palsy. Otolaryngol Clin North Am. 1991;24(3):613-45.

3. Antunes ML, Soares MCM, Vicente AO, Testa JRG, Fukuda Y. Paralisia facial periférica bilateral na leucemia linfóide aguda: relato de caso. Rev Bras Otorrinolaringol. 2004; 70(2):261-4.

4. Adams RD, Victor M, Ropper AH. Principles of neurology. $6^{\text {th }}$ ed. New York:McGrow-Hill;1997. p.1376-8.

5. Valença MM, Valença LPAA. Nervo facial: aspectos anatômicos e semiológicos. Neurobiologia. 1999;62(1):77-84.

6. Valença MM, Valença LPAA, Lima MCM. Paralisia facial periférica idiopática de Bell: a propósito de 180 pacientes. Arq Neuropsiquiatr. 2001;59(3-b):733-9.
7. Brandenburg NA, Annegers JF. Incidence and risk factores for Bell's palsy in Laredo, Texas: 1974-1982. Neuroepidemiology. 1993;12(6):313-25.

8. Savettieri G, Salemi G, Rocca WA, Meneghini F, Santangelo R, Morgante L, et al. Incidence and lifetime prevalence of Bell's palsy in two Sicilian municipalities. Sicilian Neuro-Epidemiologic Study (SNES) Group. Acta Neurol Scand. 1996;94(1):71-5.

9. Reixach-Casulá R, Galvan-Beramendi P, Potes-Sanches E. Paralisis facial periferica recidivante y alternante: aportacion de un caso con cinco episodios. Arq Neuropsiquiatr. 1982;40(4):382-4.

10. Roob G, Fazekas F, Hartung HP. Peripheral facial palsy: etiology, diagnosis and treatment. Eur Neurol. 1999;41(1):3-9.

11. Murakami S, Mizobuchi M, Nakashiro Y, Doi T, Hato N, Yanagihara $\mathrm{N}$. Bell palsy and herpes simplex virus: identification of viral DNA in endoneurial fluid and muscle. Ann Intern Med. 1996;124(1 Pt 1):27-30.

12. Steiner I, Cohen O. Peripartum Bell's palsy. Lancet. 1996;347(9008):1121-2.

13. Castañares S. Facial nerve paralyses coincident with, or subsequent to, rhytidectomy. Plast Reconstr Surg. 1974;54(6):637-43.

14. Cauás M, Valença LPAA, Andrade AFA, Martins C, Valença MM. Paralisia facial periférica recorrente. Rev Cir Traumatol Buco-Maxilo-Facial. 2004:4(1):63-8

15. Spielmann AC, Maury F, George JL. Melkersson-Rosenthal syndrome: anatomo-clinical and evolutive concepts. J Fr Ophtalmol. 2000;23(3):261-4.

16. Stahl N, Ferit T. Recurrent bilateral peripheral facial palsy. J Laryngol Otol. 1989;103(1):117-9.

17. Adour KK. Otological complications of herpes zoster. Ann Neurol. 1994;35(Suppl):S62-4.

18. Hageman G, Ippel PF, Jansen EM, Rozeboom AR. Familial, alternating Bell's palsy with dominant inheritence. Eur Neurol. 1990;30(6):310-3.

19. Kukimoto N, Ikeda M, Yamada K, Tanaka M, Tsurumachi M, Tomita H. Viral infections in acute peripheral facial paralysis. Nationwide analysis centering on CF. Acta Otolaryngol Suppl. 1988;446:17-22.

20. Lazarini PR, Vianna MF, Alcântara MPA, Scalia RA, Caiaffa Filho HH. Pesquisa do vírus herpes simples na saliva de pacientes com paralisia facial periférica de Bell. Rev Bras Otorrinolaringol. 2006;72(1):7-11.

21. Kasse CA, Cruz OLM, Leonhardt FD, Testa JRG, Ferri RG, Viertler EY. Valor prognóstico de dados clínicos em paralisia de Bell. Rev Bras Otorrinolaringol. 2005;71(4):454-8.

22. Benlyazid A, Bassereau G, Heitzmann P, Foucault N. Recurrent or familial facial palsy. Apropos of 6 cases and review of the literature. Ann Otolaryngol Chir Cervicofac. 1995;112(8):374-80.

23. Medeiros JL, Nobrega JA, de Andrade LA, Novo NF. Facial electroneurography in Bell's palsy. Variability in the early stage and comparison between interpretation methods. Arq Neuropsiquiatr. 1996;54(3):397-401.

\section{Correspondência para: Cristiano Dias da Silveira Ramos}

Rua Dr. Romualdo, 214/500 - São Mateus - Juiz de Fora, MG, Brasil - CEP 36016-380

E-mail: silveiraramos@uol.com.br 